\title{
Sacral Nerve Stimulator
}

National Cancer Institute

\section{Source}

National Cancer Institute. Sacral Nerve Stimulator. NCI Thesaurus. Code C160145.

A surgically implanted medical device that sends electrical impulses to the sacral nerve. It is used to treat bladder or bowel dysfunction. 